\title{
Analysis of Genetic Variability in Long-term Callus Cultures and Regenerated Plants of Maize
}

\author{
María del Carmen Molina ${ }^{1}$ and María Dina García ${ }^{2}$ \\ ${ }^{1}$ Instituto Fitotécnico de Santa Catalina, Facultad de Ciencias Agrarias y Forestales, Universidad Nacional de La Plata, \\ Garibaldi 3400, CC4, 1836 Llavallol, Buenos Aires, República Argentina \\ ${ }^{2}$ Facultad de Ingeniería y Ciencias Agrarias, Universidad Nacional de Lomas de Zamora, Ruta 4 Km 2, CC 95, 1832 Lomas \\ de Zamora, Buenos Aires, República Argentina
}

Accepted February 12, 1998

\begin{abstract}
Summary Zea mays ssp. mays cv. Colorado Klein organogenic calli were initiated from 11 days old embryos on basic medium containing $2.25 \mu \mathrm{M} 2,4-\mathrm{D}$. The callus originated from one of the embryos was subcultured every month to fresh medium supplemented with 4.5 or $9 \mu \mathrm{M} 2,4-\mathrm{D}$, for 84 months. The first chromosomal abnormalities appeared after 17 months of culture: $70 \%$ of regenerated plants were normal, $20 \%$ aneuploid and the remaining $10 \%$ were tetraploid. Thereafter chromosomal aberrations increased. Most (95\%) of the plants regenerated after 32 months had one extra chromosome, and meiotic analysis of regenerants showed deficiencies, duplications, inversions, translocations and ring chromosomes. Chromosome number of cells from 60 months old callus ranged from $2 n=18$ to $2 n=23$, but $90 \%$ of regenerated plants had $2 n=21$ and the remaining $10 \%$ had $2 n=20$. Plants regenerated from 64 to 84 months old callus were sterile. Also, phenotypic alterations were observed in plants regenerated from 32 months and older calli. Although original maize plants are yellow flint, $75 \%$ of $\mathrm{R} 0$ ears showed white flint kernels and their progeny exhibited yellow flint, white flint, white dent and white sugary caryopses.
\end{abstract}

Key words Somaclonal variation, Long-term callus cultures, Chromosomal abnormalities, 2,4-D, Maize regeneration.

Formerly plant tissue culture was considered as a method for cloning a particular genotype or a sophisticated technique to obtain more rapid rate of asexual propagation. However, phenotypic changes were often observed amongst regenerated plants. At first, these were seen as non-heritable variants as a consequence of "epigenetic" events (Larkin and Scowcroft 1981). Subsequently, it was corroborated that many of the variations were correlated with chromosomal aberrations (Edallo et al. 1981, Rice 1982, Karp 1995). Since then plant tissue cultures were used as a source of genetic variability for plant improvement.

Somaclonal variation is mainly correlated with numerical or structural chromosomal changes. Many authors (Pring et al. 1981, Mc Coy et al. 1982, Rhodes et al. 1986, Lee and Phillips 1987, Fluminhan et al. 1996) have documented polyploidy, aneuploidy, translocations, inversions, deletions, fragmentation, heteromorphic pairs, ring chromosomes and single gene recessive mutations in regenerants.

The frequency of chromosomal changes is affected by different aspects of tissue culture, such as species (Bayliss 1973, Novak 1981, Kirti et al. 1991, Linacero et al. 1992a, b, Kidwell et al. 1993), genotype (Li et al. 1989, Amberger et al. 1992, Cheng et al. 1992, Thorn 1992, Molina et al. 1992, Puolimatka et al. 1993), culture medium (Wilkinson et al. 1987, Amberger et al. 1992, Linacero et al. 1992a, b, Ghaemi et al. 1993), genotype-culture medium interaction (Wilkinson et al. 1987), the origin of meristematic organised growth from disorganised growth and the time spent in this state (Rhodes et al. 1986, Lee et al. 1987, Stelly et al. 1989, Qureshi et al. 1992, Karp 1995) and the concentration and type of plant growth regulators (Bai and Knott 1993). 
The current research was carried out i) to establish a long term callus culture from maize immature embryos, ii) to study phenotype and genotype stability of organogenic callus cultures and regenerated plants during 84 months of subculture on 2,4-D containing medium and iii) to evaluate the correlation between chromosomal abnormalities, somaclonal variation and fertility decrease of the regenerants.

\section{Materials and methods}

\section{Embryo culture}

Embryos of Zea mays ssp. mays cv. Colorado Klein were aseptically excised 11 days after pollination ( 1 to $2 \mathrm{~mm}$ length) and placed with the plumule radicle axis in contact with the basic medium (García et al. 1990) supplemented with $2.25 \mu \mathrm{M}$ 2,4-dichlorophenoxyacetic acid (2,4-D). The cultures were incubated 15 days at $30-32^{\circ} \mathrm{C}$ in darkness and then were exposed to a $16 \mathrm{hr}$ photoperiod. Thirty days after embryo plating, callus was cut off into small pieces and distributed on the media containing 4.5 or $9 \mu \mathrm{M} 2,4-\mathrm{D}$ and subcultured to fresh medium every 30 days. Shoots developed from callus near the end of each subculture period. Roots were induced on the basic medium supplemented with 4 or $8 \mu \mathrm{M} 4$-amino-3,5,6-trichloropicolinic acid (Picloram) or $5 \mu \mathrm{M} \alpha$-naphthaleneacetic acid (NAA) (García et al. 1992a, b).

\section{Cytogenetic analysis}

Root tips from all regenerated plants (R0) and callus were pre-treated for $3 \mathrm{hr}$ in 1,4dichlorobenzene saturated solution, fixed in $3: 1$ ethanol-glacial acetic acid and stained with Feulgen and propionic haematoxylin for mitotic analysis. Twenty calli and 10 cells from every one were analysed at each subculture step. Chromosome number was determined in 10 mitotic cells of each R0 plant.

Samples of immature tassels were also fixed in 3:1 ethanol-glacial acetic acid and anthers were squashed in $2 \%$ propionic haematoxylin and Fe for meiotic analysis (Nuñez 1968).

\section{Results}

Organogenic calli were obtained from $10 \%$ of the cultured embryos, which germinated 1 to 3 days after isolation but did not continue their normal development. A white to pale yellow callus arose from the scutellum about 7 days after plating. When cultures were transferred to $16 \mathrm{hr}$ photoperiod, green areas appeared on the callus and structures like leaves arose from them by the end of each subculture period. Shoots and roots developed on the basic medium supplemented with 4.5 or $9 \mu \mathrm{M} 2,4-\mathrm{D}$ and $5 \mu \mathrm{M}$ NAA, respectively.

Most of the organogenic calli could not regenerate plants after 16 months in culture, but exceptionally one of the embryos originated callus which have been regenerating plants for over 84 months.

Genetic analysis of the callus and plants derived from this embryo showed an increment of phenotypic and chromosomal variations during 84 months in culture. Chromosomal aberrations were positively correlated with phenotypic variations $(\mathrm{r}=0.9)$ and decrease of fertility $(\mathrm{r}=-0.85$, Fig. 1).

The genotype of R0 plants was normal until 12 months of subculturing but plants regenerated from 17 months old cultures were $20 \%$ aneuploid and $10 \%$ tetraploid.

A high frequency of plants regenerated after 32 months showed many phenotypic alterations, including phenotypes like shrunken and dwarf mutants, which were never observed before amongst original maize plants. Most of these regenerants showed one extra chromosome and abnormal meiosis with deficiencies, duplications, inversions and translocations (Table 1). 


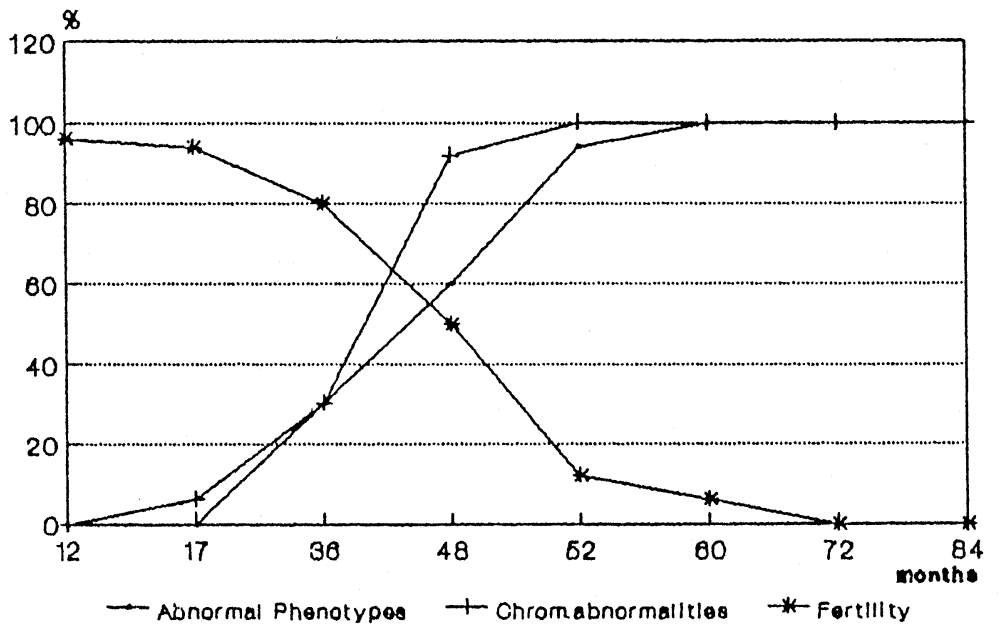

Fig. 1. Phenotypic and chromosomal abnormalities and fertility of maize plants regenerated from callus.

Table 1. Phenotypic and chromosomal analysis of maize plants regenerated from long-term callus cultures

\begin{tabular}{|c|c|c|c|c|c|c|c|c|}
\hline \multirow{2}{*}{ Genetic analysis } & \multicolumn{8}{|c|}{ Months of callus culture } \\
\hline & 12 & 17 & 32 & $48-52$ & 60 & 72 & 84 & Total \\
\hline Number of regenerants & 15 & 10 & 38 & 86 & 41 & 34 & 39 & 263 \\
\hline Number of meiotic cells & 760 & 600 & 2356 & 3440 & 1722 & 1650 & 1170 & 11698 \\
\hline \multicolumn{9}{|l|}{ Chromosome number (\%) } \\
\hline $2 n=20$ & 100 & 70 & 30 & 16 & 10 & 6 & 3 & \\
\hline $2 n=21$ & 0 & 10 & 70 & 84 & 90 & 94 & 97 & \\
\hline $2 n=23$ & 0 & 10 & 0 & 0 & 0 & 0 & 0 & \\
\hline $2 n=40$ & 0 & 10 & 0 & 0 & 0 & 0 & 0 & \\
\hline Univalents $(\%)$ & 2 & 15 & 28 & 40 & 62 & 60 & 74 & \\
\hline Deficiencies (\%) & 0 & 0 & 7 & 18 & 21 & 32 & 35 & \\
\hline Duplications (\%) & 0 & 0 & 8 & 25 & 26 & 30 & 28 & \\
\hline Inversions $(\%)$ & 0 & 0 & 16 & 20 & 23 & 34 & 40 & \\
\hline Translocations (\%) & 0 & 0 & 5 & 12 & 7 & 18 & 20 & \\
\hline Ring chromosomes $(\%)$ & 0 & 0 & 0 & 0 & 12 & 15 & 17 & \\
\hline Phenotypic variants $(\%)$ & 0 & 4 & 36 & 98 & 100 & 100 & 100 & \\
\hline Fertility (\%) & 98 & 96 & 80 & 17 & 14 & 0 & 0 & \\
\hline
\end{tabular}

Chromosome number from 60 and 84 months old callus cells was very variable with $2 n=18$, 19, 20, 2122 and 23. Besides, some cells showed chromosomes with satellite, heteromorphic pairs and ring chromosomes (Fig. 2). However, regenerants were $2 n=20$ or 21 and their meiotic analysis revealed the same abnormalities found in plants regenerated after 52 months of subculturing as well as a high number of univalents and ring chromosomes (Table 1). The $30 \%$ of these plants showed normal anaphase and the remaining $70 \%$ had different chromosome number in each pole and one or more chromatid bridges (Fig. 3). The callus still regenerated plants after 64 months but they were completely sterile (Fig. 4).

R0 plants from 32 months old callus were self-pollinated to obtain their progeny (R1). The $75 \%$ of R0 ears exhibited white flint kernels. The R1 plants showed many phenotypic alterations: plant height from 20 to $150 \mathrm{~cm}$, plants with 2 ears at the same node, non branched tassels, coloured anthers, albino plants, tiller plants, characteristics of dwarf and shrunken mutants, precocity and tassel seed. 

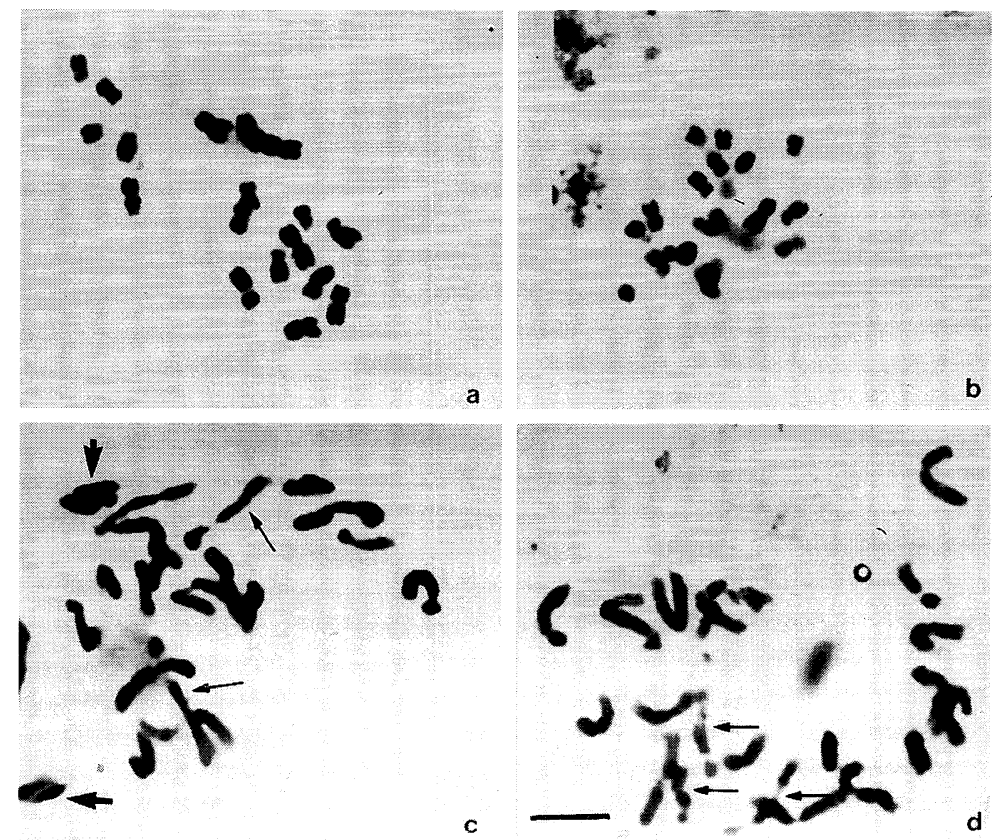

Fig. 2. Karyotypes of cells from 84 months old maize callus. a) $2 n=18$; b) $2 n=19$; c) $2 n=21$; Note 2 ring chromosomes $(\longrightarrow$ ) and 2 chromosomes with satellite $(\longrightarrow$ ); d) $2 n=22$. The arrows show 3 chromosomes with satellite. Scale bar represents $10 \mu \mathrm{m}$.
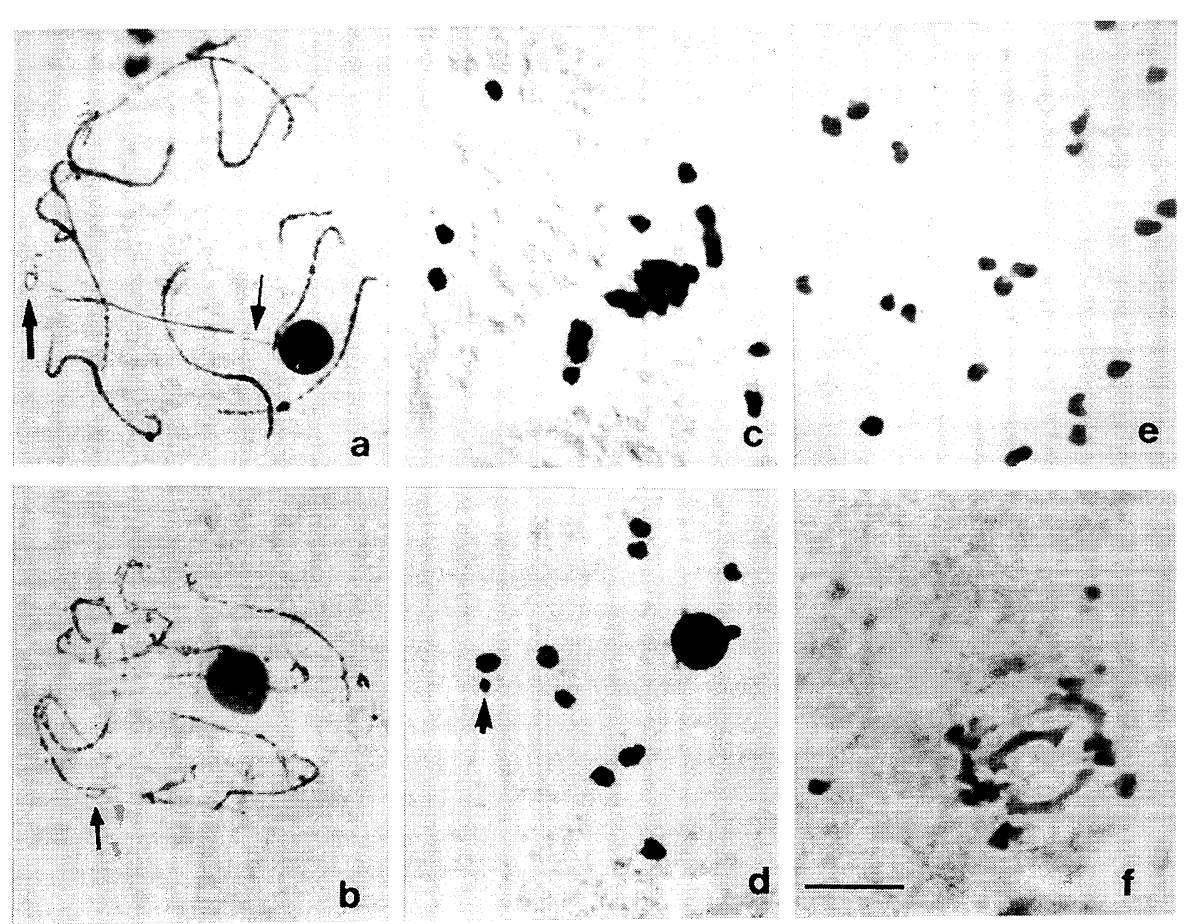

Fig. 3. Meiotic abnormalities in maize plants regenerated from 84 months old callus. a, b) Pachynema; a) Deficiencies $(\longrightarrow$ ) and one extra chromosome ( $\longrightarrow$ ); b) Duplications; c) Metaphase I with 7 univalents; d,e) Diakinesis; d) One extra chromosome; e) All univalent chromosomes; f) Anaphase showing 3 chromatid bridges. Scale bar represents $10 \mu \mathrm{m}$. 


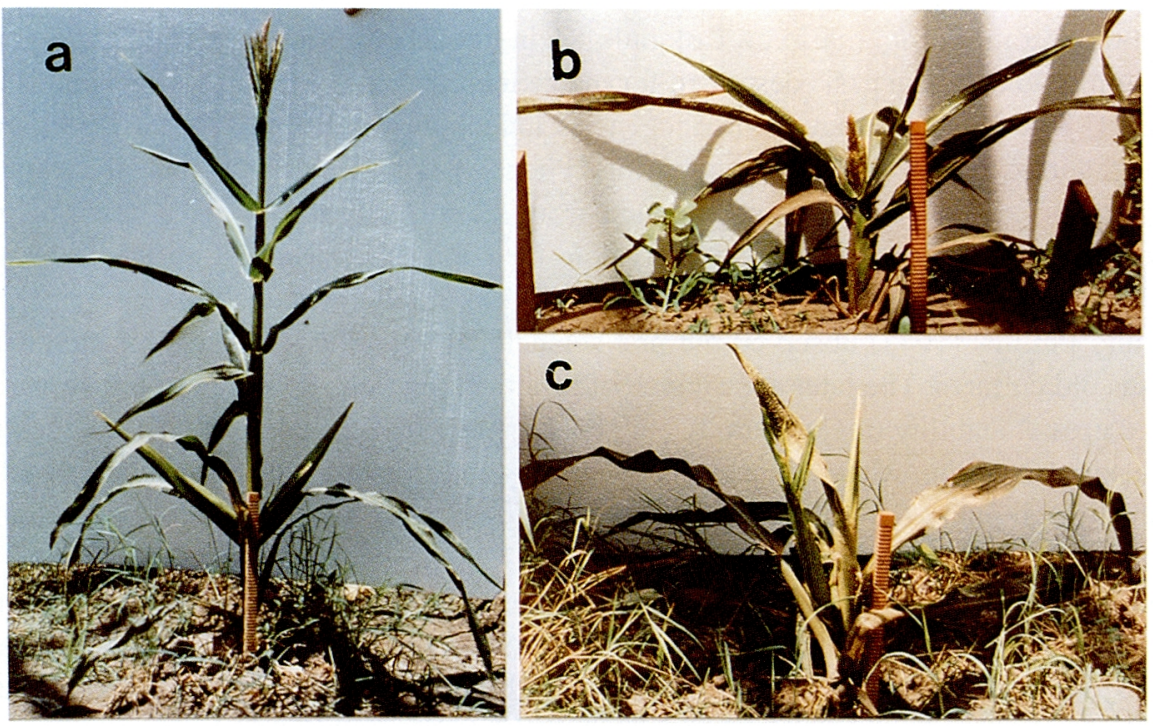

Fig. 4. Plants of maize cv. Colorado Klein regenerated from callus cultures. a) From 12 months old callus; b, c) From 84 months old callus. Rule $=20 \mathrm{~cm}$.

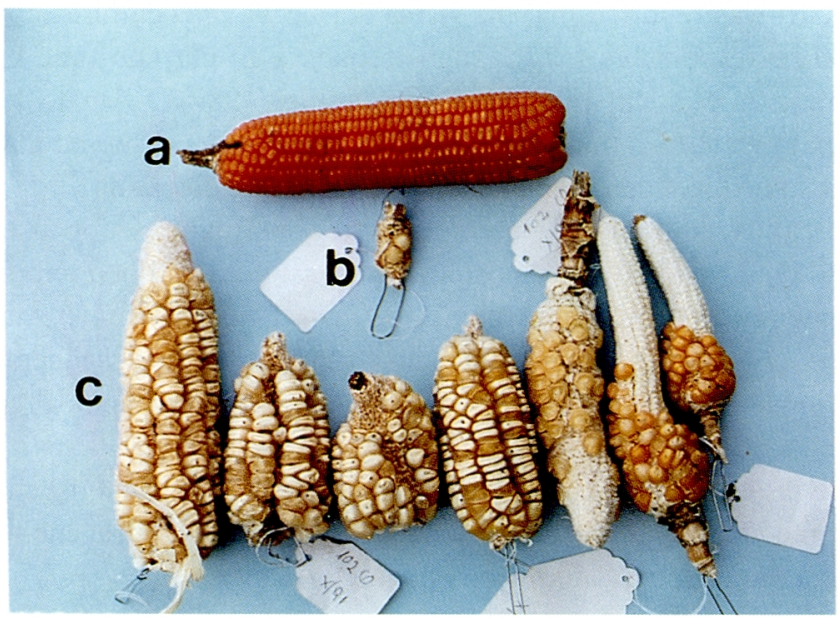

Fig. 5. Female inflorescences of maize cv. Colorado Klein obtained from: a) Original cv. Colorado Klein plants; b) R0 plants regenerated from 52 months old callus; c) R1 plants originated from ear b.

The R1 plants obtained from white flint kernels were self-pollinated and the analysis of the ears showed the further variants (Fig. 5):

- Yellow flint caryopsis like the original population.

- Yellow and white flint caryopsis.

- White dent and sugary caryopsis in the rate $3: 1$. 


\section{Discussion}

Plant regeneration from maize cv. Colorado Klein immature embryos showed a morphogenetic pathway similar to organogenesis described for maize inbreds Black Mexican Sweet and A188 (Van Lammeren 1988). The frequency of organogenesis induction was low (10\%), but 328 plants were regenerated during 84 months of subculturing. Phenotypic and chromosomal abnormalities increased from 0 to $100 \%$ in plants regenerated from 12 to 60 months old cultures, respectively. Thereafter regenerated plants were completely deformed and sterile. Similar observations were also reported by Green and Phillips (1975), Green et al. (1977), Edallo et al. (1981).

Lee and Phillips (1987) observed the first somaclonal variations in plants regenerated from 3 to 8 months old cultures. The later appearance of genetic alterations observed in this research could be due to a greater stability of Colorado Klein genotype in vitro or the lower 2,4-D concentration in the maintenance medium, when compared with media used by other authors. Bai and Knott (1993) verified that the amount of 2,4-D and the time in culture increase both chromosomal and phenotypic abnormalities of regenerated plants.

The most frequently observed chromosomal alterations were little intercalar or terminal deficiencies, extra chromosomes, inversions, translocations and univalents. This agree with many reports (Benzion 1984, Green et al. 1977, Mc Coy and Phillips 1982, Lee et al. 1987, D'Amato 1991) which describe maize chromosome inversions, translocations and extra chromosomes caused by chromosome breaking and interchange induced by tissue culture.

Although all analysed plants were generated from a single maize embryo, those regenerated from 17 months and older cultures had different genotypes and phenotypes and some plants showed recessive gene mutations, such as Shrunken or Dwarf, which never appeared in the original Colorado Klein phenotype. It was reported that the stress during in vitro culture activates transposable elements, which would be responsible for the high frequency of chromosome breakage, recessive mutations and the expression of silent genes (Lee and Phillips 1987, D'Amato 1991). Mc Clintock (1956), Mazoti (personal communication) and Kermicle (1980) also observed maize somatic mutations caused by chromosome breakage in plants with transposable elements.

Sixty months old callus showed some chromosomal abnormalities, for instance cell chromosome numbers $2 \mathrm{n}=18,19,22$ and 23, chromosomes with satellite and heteromorphic pairs, which were not found in regenerants. All of them were $2 n=20$ or 21 , which implies that arose from cells with that chromosome number. Only some callus cells were able to rise regenerants, so the lack of regeneration ability in long-term callus cultures could be due to some genetic alterations induced by somaclonal variation.

In conclusion, a long-term (84 months) maize callus culture was established from one embryo on a 2,4-D containing medium. The longer the culture time, callus and regenerants increased progressively their genetic, chromosomal and phenotypic abnormalities.

\section{Acknowledgements}

The authors are grateful to Ing. Agr. Víctor R. Corcuera for critical reading of the manuscript. This work was supported by CONICET, Universidad Nacional de La Plata and Universidad Nacional de Lomas de Zamora.

\section{References}

Amberger, L. A., Palmer, R. G and Shoemaker, R. C. 1992. Analysis of culture-induced variation in Soybean. Crop Sci. 32: $1103-1108$.

Bai, D. and Knott, D. R. 1993. The effects of level of 2,4-D and time in culture on regeneration rate and chromosome number of regenerants from calli of the hybrid Triticum aestivum cv. Chinese Spring ph $1 \mathrm{~b} \times$ Thinopyrum ponticum 
$(2 \mathrm{n}=10 \mathrm{x}=70)$. Genome 36: $166-172$.

Bayliss, M. W. 1973. Origin of chromosome number variation in cultured plant cells. Nature 246: 21-28.

Benzion, G. 1984. Genetic and cytogenetic analysis of maize cultures: a cell line pedigree analysis. Ph. Dissertation University of Minnesota.

Cheng, X. Y., Gao, M. W., Liang, Z. Q., Liu, G. Z. and Hu, T. C. 1992. Somaclonal variation in winter wheat: frequency, occurrence and inheritance. Euphytica 64: 1-10.

D’Amato, F. 1991. Nuclear changes in cultured plant cells. Caryologia 44: 217-224.

Edallo, S., Zucchinali, C., Perenzin, M. and Salamini, F. 1981. Chromosomal variation and frequency of spontaneous mutation associated with in vitro culture and plant regeneration in maize. Maydica 26: 39-56.

Fluminhan, A., de Aguiar-Perecin Jr., M. L. R. and Dos Santos, J. A. 1996. Evidence for heterochromatin involvement in chromosome breakage in maize callus culture. Annals of Botany 78: 73-81.

García, M. D., Molina, M. del C. and Caso, O. H. 1990. Regeneration in callus cultures and cytological analysis of regenerated plants. Maize Genetic Coop. Newsletter 64: 72-73.

-, - and - 1992a. El cultivo de callos organogénicos como fuente de variabilidad genética para el mejoramiento del maíz. Revista del V Congreso Nacional del Maíz-II Reunión Suramericana de Maiceros, Pergamino, Buenos Aires. I: $61-69$.

- - - and - 1992b. La regeneración de plantas de maiz (Zea mays ssp. mays) a partir del cultivo de tejidos y su aplicación en el mejoramiento genético. Rev. de la Fac. de Agron. de la U.N.L.P. 68: 15-25.

Ghaemi, M. A., Sarrafi, A. and Alibert, G. 1993. Influence of genotype and culture conditions on the production of embryos from anthers of tetraploid wheat (Triticum turgidum). Euphytica 65: 81-85.

Green, C. E. and Phillips, R. L. 1975. Plant regeneration from tissue culture of maize. Crop Sci. 15: 417-421.

- - - and Wang, A. S. 1977. Cytological analysis of plants regenerated from maize tissue culture. Maize Genetic Coop. Newsletter 51: 53-54.

Karp, A. 1995. Somaclonal variation as a tool for crop improvement. Euphytica 85: 295-302.

Kermicle, J. L. 1980. Probing the component structure of a maize gene with transposable elements. Science 208: 1459-1461.

Kidwell, K. K. and Osborn, T. C. 1993. Variation among alfalfa somaclones in copy number of repeated DNA sequences. Genome 36: 906-912.

Kirti, P. B., Hadi, S., Kumar, P. A. and Chopra, V. L. 1991. Production of Sodium-chloride-tolerant Brassica juncea plants by in vitro selection at the somatic embryo level. Theor. Appl. Genet. 83: 233-237.

Larkin, P. J. and Scowcroft, W. R. 1981. Somaclonal variation - a novel source of variability from cell cultures for plant improvement. Theor. Appl. Genet. 60: 197-214.

Lee, M. and Phillips, R. L. 1987. Genomic rearrangements in maize induced by tissue culture. Genome 29: 122-128.

Li, R. and Stelly, D. M. 1989. Cytogenetic abnormalities in Cotton (Gossipium hirsutum L.) cell cultures. Genome 32: 1128-1134.

Linacero, R. and Vazquez, A. M. 1992a. Genetic analysis of chlorophyll deficient somaclonal variants in rye. Genome 35: 981-984.

— and - 1992b. Cytogenetic variation in rye regenerated plants and their progeny. Genome 35: 428-430.

Mc Clintock, B. 1956. Controlling elements and the gene. Cold Spring Harbor Symp. Quant. Biol. 21: 197-216.

Mc Coy, T. J. and Phillips, R. L. 1982. Chromosome stability in maize (Zea mays L.) tissue culture and sectoring in some regenerated plants. Can. J. Genetic. Cytol. 24: 559-565.

Molina, M. del C. and García, M. D. 1992. Phenotypic and chromosomic aberrations in maize plants regenerated from callus. Maize Genet. Coop. Newsletter 66: 64-65.

Novak, F. J. 1981. Chromosomal characteristics of long-term callus cultures of Allium sativum L. Cytologia 46: 371-379.

Nuñez, O. 1968. An acetic haematoxylin squash method for small chromosomes. Caryologia 21: 115-119.

Pring, D. R., Conde, M. F. and Gengenbach, B. G. 1981. Cytoplasmic genome variability in tissue culture-derived plants. Env. Exp. Bot. 21: 369-377.

Puolimatka, M. and Karp, A. 1993. Effect of genotype on chromosome variation in tissue culture of inbred and outbred rye. Heredity 71: 138-144.

Qureshi, J. A., Huel, P. and Kartha, K. K. 1992. Is somaclonal variation a reliable tool for spring wheat improvement? Euphytica 60: 221-228.

Rhodes, C. A., Phillips, R. L. and Green, C. E. 1986. Cytogenetic stability of aneuploid maize tissue culture. Can. J. Genet. Cytol 28: 374-384.

Rice, T. B. 1982. Tissue culture induced variation in regenerated maize inbred. In "Proceeding of the Thirty-seventh Annual Corn and Sorghum Industry Research Conference. American Seed Trade Association, Washington D.C. 148-162.

Stelly, D. M., Altman, D. W., Kohel, R. J., Rangan, T. S. and Commiskey, E. 1989. Cytogenetic abnormalities of cotton somaclones from callus cultures. Genome 32: $762-770$.

Thorn, E. C. 1992. The influence of genotype and environment on seed and embryo development in barley (Hordeum vul- 
gare L.) after crossing with Hordeum bulbosum L. Euphytica 59: 109-118.

Van Lammeren, A. A. 1988. Observations on the structural development on immature maize embryos (Zea mays L.) during in vitro culture in the presence or absence of 2,4-D. Acta Bot. Neerl. 37(1): 49-61.

Wilkinson, T. C. and Thompson, S. A. 1987. Genotype, medium and genotype $\times$ medium effects on the stablishment of regenerable maize callus. Maydica 32: 89-105. 